\title{
Predicting feeding value of forage maize hybrids harvested at different maturities and sites
}

\author{
S.J. Krizsan ${ }^{1,4}$, Z. Mussadiq ${ }^{1,2}$, M. Hetta ${ }^{1}$, M. Ramin ${ }^{1}$, L. Nyholm ${ }^{3}$ and P. Huhtanen ${ }^{1}$ \\ ${ }^{1}$ Swedish University of Agricultural Sciences, Department of Agricultural Research for Northern Sweden \\ SE-901 83 Umeå, Sweden \\ ${ }^{2}$ Szent Istaván University, Faculty of Agricultural and Environmental Sciences, H-2100 Gödöllö, Hungary (present address) \\ 3 Valio Ltd., Farm Services, PO Box 10, FI-00039 Valio, Finland
}

KEY WORDS: indigestible neutral detergent fibre, near-infrared reflectance spectroscopy, NIRS, organic matter digestibility, maize
Received: 2 December 2013

Revised: 27 May 2014

Accepted: 21 August 2014

${ }^{4}$ Corresponding author:

e-mail: sophie.krizsan@slu.se

\begin{abstract}
The objective of this study was to evaluate two near-infrared reflectance spectroscopy (NIRS) applications and different laboratory methods for determining indigestible neutral detergent fibre (iNDF) and organic matter digestibility (OMD) of forage maize hybrids harvested at high latitudes. Different in situ and in vitro methods have been used in calibrations of NIRS for routine determinations of forage feed value in the Nordic countries. Swedish and Finnish NIRS calibrations of iNDF generated biased estimates of low precision of iNDF determined in situ. All methods used to predict OMD in forage maize systematically underestimated the observed OMD calculated from the in situ determined value of iNDF. Digestibility was determined with least precision based on the enzymatic in vitro procedure. Values of OMD based on the in vitro incubation in buffered rumen fluid displayed the smallest error among the laboratory methods. The NIRS calibration developed with the forage maize samples of this study, suggested that NIRS has a great potential to predict iNDF and OMD of forage maize accurately and precisely. It was concluded that NIRS predictions of OMD can be a promising tool for evaluating performance of forage maize hybrids at high latitudes if NIRS calibrations of iNDF including forage maize samples are available.
\end{abstract}

\section{Introduction}

Forage maize (Zea mays L.) cultivation has been increasing in Northern Europe in recent years as a result of the development of early maturing hybrids and improved agronomic practices. Land used for cultivation of forage maize has increased almost ten-fold in Sweden since the crop was introduced in 1980's (Jordbruksverket, 2010). Yield and nutrient composition varies with hybrid, stage of maturity at harvest, and climatic conditions across locations used for forage maize cultivation in Sweden (Swensson et al., 2008). An accurate prediction of feed value is important for correct ranking of the performance of hybrids in plant breeding programmes. Digestibility is the most important trait of forages in feed value determinations (Huhtanen et al., 2006). Digestibility of organic matter (OM) in forage maize is positively related to high concentrations of starch and sugar, which are almost completely digestible in ruminants (Bal et al., 1997; Sutton et al., 2000). However, forage maize harvested at a more immature growth stage has less starch, but higher digestibility of neutral detergent fibre 
(NDF) resulting in a possible small overall effect of increasing plant maturity on $\mathrm{OM}$ digestibility (OMD) (Givens and Deaville, 2001).

There are different analytical methods applied for the predictions of OMD in forages in the Nordic countries (Huhtanen et al., 2006; Åkerlind et al., 2011). Different in vitro methods related to in vivo OMD have been used for calibration of near infrared reflectance spectroscopy (NIRS) for routine determinations of forage OMD. Values reported to farmers are based on the country-specific reference laboratory method, which is affected by interactions between forage type and method (Krizsan et al., 2012). The reference laboratory method for forage maize in Denmark is an enzymatic 2-step in vitro procedure based on a mixture of enzymes degrading starch and fibre (Weisbjerg and Hvelplund, 1993). In Sweden, OMD in forage maize is predicted by a single $96-\mathrm{h}$ in vitro incubation based on rumen fluid (Lindgren, 1979). Predictions of forage OMD performed almost equally well based on the 96-h in vitro incubation method as when predicted from indigestible NDF (iNDF) determined from a 288-h ruminal in situ incubation (Krizsan et al., 2012). It has been shown, however, that in situ was a more uniform method and would improve overall predictions of forage in vivo OMD at commercial laboratories in Nordic countries (Huhtanen et al., 2006; Krizsan et al., 2012). The performance of these analytical methods as predictors of OMD has not been evaluated for forage maize grown at higher latitudes before. The objective of this study was to evaluate the potential of NIRS calibrations of iNDF for feed value determination of forage maize, and to evaluate different laboratory methods used for predictions of in vivo OMD of forage maize hybrids harvested at different sites and stages of maturity at high latitudes.

\section{Material and methods}

\section{Maize samples and chemical analysis}

The plant material used to assess the different laboratory methods consisted of 72 samples of three forage maize hybrids harvested at four occasions with increasing maturity at three different geographical sites in Sweden. The hybrids were of different maturity indices as classified according to the Food and Agricultural Organization of the United Nations (FAO): Avenir with FAO 180 (Syngenta Seeds, Basel, Switzerland) and Isberi and Burli with FAO 190 and 210, respectively (Caussade Semences, Caussade, France). Samples were collected in an agronomic study of forage maize conducted by Mussadiq et al. (2012) during the 2009 growing season
Table 1. Descriptive statistics for the measured and predicted parameters $\left(\mathrm{g} \cdot \mathrm{kg}^{-1} \mathrm{dry}\right.$ matter unless otherwise stated) of all maize hybrid samples collected at all sites $(n=72)$

\begin{tabular}{lrrrr}
\hline Parameters $^{1}$ & Mean & \multicolumn{1}{c}{$\mathrm{SD}^{2}$} & \multicolumn{2}{c}{ Minimum Maximum } \\
\hline Dry matter, $\mathrm{g} \cdot \mathrm{kg}^{-1}$ & 242 & 58.2 & 150 & 433 \\
Organic matter & 952 & 8.1 & 929 & 972 \\
Crude protein & 80 & 18.5 & 44 & 123 \\
Neutral detergent fibre & 490 & 61.7 & 340 & 594 \\
Starch & 151 & 90.8 & 8 & 359 \\
Water soluble carbohydrates & 102 & 56.1 & 13 & 230 \\
EFOS, $\mathrm{g} \cdot \mathrm{kg}^{-1}$ & 653 & 42.2 & 535 & 750 \\
VOS, $\mathrm{g} \cdot \mathrm{kg}^{-1}$ & 777 & 26.7 & 703 & 844 \\
iNDF $_{\text {INSITU }}$ & 113 & 21.6 & 65 & 165 \\
iNDF $_{\text {NIRS-S }}$ & 105 & 18.8 & 70 & 158 \\
iNDF $_{\text {NIRS-F }}$ & 142 & 20.5 & 85 & 196 \\
iNDF $_{\text {NIRS-M72 }}$ & 113 & 20.8 & 64 & 171 \\
OMD $_{\text {IN SITU }} \mathrm{g} \cdot \mathrm{kg}^{-1}$ & 693 & 29.7 & 621 & 757 \\
OMD $_{\text {EFOS }} \cdot \mathrm{g} \cdot \mathrm{kg}^{-1}$ & 679 & 30.8 & 593 & 749 \\
OMD $_{\text {VOS }} \cdot \mathrm{g} \cdot \mathrm{kg}^{-1}$ & 679 & 24.0 & 612 & 739 \\
OMD $_{\text {NRS-F }} \cdot \mathrm{g} \cdot \mathrm{kg}^{-1}$ & 678 & 30.2 & 594 & 736 \\
\hline
\end{tabular}

${ }^{1}$ EFOS - enzyme digestible organic matter; VOS - rumen fluid organic matter solubility; NNDF $_{\text {IN SITU }}$ - indigestible neutral detergent fibre (iNDF) determined from a 288-h ruminal in situ incubation in dairy cows; iNDF $_{\text {NRS-S }}$ - from the Swedish near infrared reflectance spectroscopy (NIRS) calibration; iNDF NIRS-F $_{-}$- from the Finnish NIRS calibration; iNDF $_{\text {NIRS-M72 }}$ - from the NIRS calibration developed in this study; $\mathrm{OMD}_{\text {IN SITU }}$ - organic matter digestibility (OMD) calculated based on the iNDF determined by the 288-h ruminal in situ incubation (Huhtanen et al., 2013); $\mathrm{OMD}_{\mathrm{EFOS}}$ - predicted from EFOS (Weisbjerg and Hvelplund, 1993); $O M D_{\text {vos }}$ - predicted from VOS (Lindgren, 1979); $\mathrm{OMD}_{\text {NIRS-F }}$ - predicted based on the Finnish NIRS calibration; ${ }^{2} \mathrm{SD}$ - standard deviation

from Kristianstad (N 56 ${ }^{\circ}$; E $14^{\circ}$ ), Skara (N 58 ;

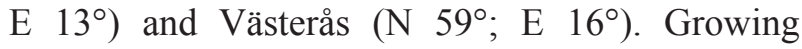
conditions, cultivation, agronomic performance and nutritional qualities of the material have been described in detail by Mussadiq et al. (2012). Briefly, a randomized complete block design with two replicated blocks at each site was used. Plants were harvested on four occasions and in two replicates, which resulted in 24 samples at each site. After drying, plant samples were ground through a $2.0-\mathrm{mm}$ screen for in situ incubations, and a $1.0-\mathrm{mm}$ screen for in vitro incubations and chemical analysis using a Retsch SM 2000 Mill (Haan, Germany). Descriptive statistics of chemical composition across hybrids, sites and harvests of plant material are presented in Table 1.

\section{In situ and in vitro methods}

Concentrations of iNDF in forage maize samples were determined following a 288-h in situ incubation (Huhtanen et al., 1994) using three ruminally cannulated lactating Swedish Red cows. The cows were fed a diet consisting of 600 and $400 \mathrm{~g} \cdot \mathrm{kg}^{-1}$ diet dry matter (DM) of grass silage 
and concentrate (Vida 175; Lantmännen Lantbruk $\mathrm{AB}$, Stockholm, Sweden), respectively, to meet production requirements. Samples of $2 \mathrm{~g}$ were weighed into pre-weighed polyester bags with pore size of $12 \mu \mathrm{m}$ and a pore area equal to $6 \%$ of the total surface (Saatifil PES 12/6; Saatitech S.P.A., Veniano, Como, Italy). The sample size to surface area ratio was $10 \mathrm{mg} \cdot \mathrm{cm}^{2}$. After removal from the rumen, bags were rinsed in a household washing machine (the rinsing part of the wool wash programme) including three times washing for 2.5 min per washing (including the time for filling of water) using approximately $8^{\circ} \mathrm{C}$ water (Electrolux Wascator W75MP; AB Electrolux, Stockholm, Sweden). Thereafter, the bags were boiled for $1 \mathrm{~h}$ in neutral detergent solution including sodium sulphite $\left(100 \mathrm{ml} \cdot \mathrm{g}^{-1}\right.$ of sample; Mertens et al., 2002), thoroughly rinsed, dried at $60^{\circ} \mathrm{C}$ for $24 \mathrm{~h}$ and weighed.

The enzymatic solubility of the forage maize samples was determined from a 2-step enzymatic in vitro digestion of OM (EFOS; abbreviated based on the Danish term enzym fordøjelig organisk stof) according to Weisbjerg and Hvelplund (1993). In this method, initially $500 \mathrm{mg}$ of sample was subjected to a pre-treatment with pepsin- $\mathrm{HCl}(1000 \mathrm{ml}$ of $0.5 \mathrm{M} \mathrm{HCl}$ and $2 \mathrm{~g}$ pepsin; Pepsin Orthana, $10000 \mathrm{NF} U \cdot \mathrm{g}^{-1}$; VWR, Kastrup, Denmark). Samples were then moved to a water bath maintained at $80^{\circ} \mathrm{C}$ for $45 \mathrm{~min}$. The second step of digestion was performed by incubating the samples for $24 \mathrm{~h}$ at $40^{\circ} \mathrm{C}$ in $30 \mathrm{ml}$ of an enzyme mixture consisting of cellulase $\left(20 \mathrm{ml}\right.$ Cellulast, $798 \mathrm{EGU} \cdot \mathrm{g}^{-1}$; Novozymes, Bagsværd, Denmark), hemicellulase (10 $\mathrm{ml}$ Viscozyme L., $120 \mathrm{FBG} \cdot \mathrm{ml}^{-1}$; Novozymes, Bagsværd, Denmark), amyloglucosidase (2.135 g Megazyme E-AMGDF, $3260 \mathrm{U} \cdot \mathrm{ml}^{-1}$; Megazyme Int., Wicklow, Ireland) and Novozyme 51054 (17 $\mathrm{ml}, 1000 \mathrm{k} \mathrm{VHCV}(\mathrm{m}) \cdot \mathrm{g}^{-1}$; Novozymes, Bagsværd, Denmark) dissolved in $1000 \mathrm{ml} 0.1 \mathrm{M}$ acetate buffer. Samples in enzyme mixture were incubated additionally for $19 \mathrm{~h}$ at $60^{\circ} \mathrm{C}$ before washing with hot water and acetone. Finally, residues were dried overnight at $103^{\circ} \mathrm{C}$ weighed and thereafter combusted at $525^{\circ} \mathrm{C}$ for $6 \mathrm{~h}$ for determination of residual ash.

Rumen fluid digestible OM (VOS; abbreviated based on the Swedish term vomvätskelöslig organisk substans) was determined by a single 96 -h incubation of forage samples in rumen fluid as described by Lindgren (1979). Rumen fluid digestible OM was determined from incubating $500 \mathrm{mg}$ of dried forage maize samples in $49 \mathrm{ml}$ buffer and $1 \mathrm{ml}$ of rumen fluid at $38^{\circ} \mathrm{C}$. Incubation residues were dried at $105^{\circ} \mathrm{C}$ for $3 \mathrm{~h}$, weighed and thereafter combusted at $500^{\circ} \mathrm{C}$ for $40 \mathrm{~min}$ for determination of residual ash.

\section{Near infrared reflectance spectroscopy predictions of iNDF}

The calibration of NIRS for prediction of iNDF in Swedish farm samples (iNDF ${ }_{\text {NIRS-s) }}$ was developed as follows. Reference samples that had been analysed at different Scandinavian research laboratories were ground through a $1.0-\mathrm{mm}$ screen in a hammer mill (Kamas Slagy 200B; Kamas Kvarnindustrier AB, Malmö, Sweden) and then scanned (wavelength range 400 to $2500 \mathrm{~nm}$, $2 \mathrm{~nm}$ intervals) with a NIR 6500 instrument (FOSS Analytical A/S, Hillerød, Denmark). Spectral data for wavelengths between 1100 and $2498 \mathrm{~nm}$ were transformed by applying mathematical treatment of the second order derivative $(2,10,10,1$ in which the values represent the number of the derivative, the gap over which the derivative is calculated, the number of points in moving average and the number of nm over which the second smoothing is applied, respectively), along with standard normal variate and detrend scatter correction (SNV\&D). Samples in the calibration set consisted of fresh grass $(n=19)$, grass silages $(n=27)$, grass-clover silages $(n=16)$, fresh forage legumes $(n=50)$, whole crop cereal silages $(n=15)$, straw $(n=7)$ and forage maize samples $(n=13$ of silages and $n=65$ of fresh material), giving a total of 212 observations for iNDF concentrations. In all laboratories reference iNDF concentration was determined by 288-h ruminal in situ incubations in dairy cows using small pore size nylon bags of $12 \mu \mathrm{m}$ according to the Nordic feed evaluation system standard (Åkerlind et al., 2011). A partial least square regression algorithm using six cross validation segments was applied for calibration and validation. The $\mathrm{iNDF}_{\text {NIRS-s }}$ prediction was made from the dried forage maize samples ground through a 1-mm screen using a hammer mill (Kamas Slagy 200B; Kamas Kvarnindustrier AB, Malmö, Sweden) and scanned with a NIR InfraXact instrument (FOSS Analytical A/S, Hillerød, Denmark). Predicted iNDF concentrations were based on scanning across a wavelength range of 400 to $2500 \mathrm{~nm}$ at $2 \mathrm{~nm}$ intervals and using the NIRS calibration described above.

For NIRS predictions in Finland, dried forage maize samples were ground through a $0.8 \mathrm{~mm}$ screen with a Laboratory Mill 3100 (Danfoss AB, Linköping, Sweden) before being scanned with a NIR systems XDS (FOSS Analytical A/S, Hillerød, Denmark). Samples were scanned through a wavelength range of 400 to $2500 \mathrm{~nm}$ at $2 \mathrm{~nm}$ intervals and trimmed to a NIRS region of 1100 to $2498 \mathrm{~nm}$. The NIRS calibrations for iNDF and digestible OM in the DM (D-value) were developed with WinISI ${ }^{\mathrm{TM}} 4$ 
software (FOSS Analytical A/S, Hillerød, Denmark) using spectral data between 1100 and $2498 \mathrm{~nm}$. A modified partial least square regression method (MPLS) using four cross-validation groups was applied for calibration and cross-validation. The external validation of $\mathrm{D}$-value calibration was carried out with 50 samples not included in the calibration data set. The mathematical transformation included second order of derivative $(2,4,4,1)$, along with SNV\&D. The iNDF ( $\mathrm{iNDF}_{\text {NIRS-F }}$ ) and D-value predictions generated from the Finnish NIRS instrument were based on a combined silage-grass calibration consisting of samples of fresh forages (including legumes, and red clover and grass mixtures; $n=116$ and 198), grass silages ( $\mathrm{n}=278$ and 427), legume silages (including pure red clover and lucerne silages, and legume and grass silage mixtures; $n=41$ and 59), whole crop silages (different crops and mixtures, also mixtures with pea and bean, but no forage maize samples; $n=26$ and 86) and straw ( $\mathrm{n}=0$ and 11), giving a total of 461 and 781 observations for iNDF and D-value, respectively. Ruminal in situ incubations for 288-h in dairy cows using small pore size nylon bags $(6-17 \mu \mathrm{m})$ was used as reference method for the NIRS calibration of iNDF. In vitro pepsin-cellulase solubility of OM validated against in vivo OMD determined in sheep fed at maintenance level of feeding was used as reference method in the Finnish NIRS calibration of D-value (Nousiainen et al., 2003).

To challenge the present iNDF calibrations based on multiple species, a new NIRS iNDF calibration for the 72 forage maize samples ( $\mathrm{iNDF}_{\mathrm{NIRS}-\mathrm{M} 72}$ ) was developed with the WinISITM 4 software using Finnish NIRS scans resulting in spectral data between 1100 to $2500 \mathrm{~nm}$. The calibrations were calculated with the MPLS method. Mathematical treatments of the first and second order derivatives $(1,4,4,1$ or $2,4,4,1)$ were used to enhance the spectral differences, and SNV\&D was used as a scatter correction method. Calibration accuracy was evaluated by cross validation splitting data set to 4 subsets. The best NIRS calibration model was selected based on coefficient of determination $\left(R^{2}\right)$, cross validated coefficient of determination (1-VR), standard error of cross validation (SECV) and the standard deviation (SD)/SECV.

\section{Prediction equations of OMD}

The OMD (given in $\mathrm{g} \cdot \mathrm{kg}^{-1}$ in all equations below) calculated from in situ incubation values and NDF concentrations $\left(\mathrm{OMD}_{I N \text { SITU }}\right)$ was used as observed values in this study. The OMD $\mathrm{OMINU}_{\text {SITU }}$ was determined according to Huhtanen et al. (2013; equation 1):

$$
\mathrm{OMD}_{\text {IN SITU }}=882-1.21 \times \mathrm{iNDF}-0.106 \times \mathrm{NDF}
$$

where: concentrations of iNDF and NDF are given in $\mathrm{g} \cdot \mathrm{kg}^{-1} \mathrm{DM}$.

Predicted OMD from EFOS values (OMD $\left.{ }_{\text {EFOS }}\right)$ for all samples was determined according to Søegaard et al. (2001; equation 2):

$$
\mathrm{OMD}_{\mathrm{EFOS}}=204+0.727 \times \mathrm{EFOS}
$$

where: concentration of EFOS is given in $\mathrm{g} \cdot \mathrm{kg}^{-1} \mathrm{DM}$.

Predicted OMD from VOS values $\left(\mathrm{OMD}_{\mathrm{vos}}\right)$ for all samples was determined according to Lindgren (1983; equation 3):

$$
\text { OMDVOS }=-20+0.90 \times \operatorname{VOS}
$$

where: concentration of VOS is given in $\mathrm{g} \cdot \mathrm{kg}^{-1} \mathrm{DM}$.

Predicted OMD from Finnish NIRS calibration generated D-values $\left(\mathrm{OMD}_{\text {NIRS-F }}\right)$ was calculated according to equation 4 :

$$
\mathrm{OMD}_{\text {NIRS-F }}=\mathrm{D} \text {-value } \times 1000 / \mathrm{OM}
$$

where: D-value and $\mathrm{OM}$ are given in $\mathrm{g} \cdot \mathrm{kg}^{-1} \mathrm{DM}$.

\section{Statistical analysis}

All predictions were evaluated by linear regression. Observed values (y) were plotted against model predicted values (x) and a regression equation was fitted. Hypothesis testing (the slope is not different from unity) was conducted based on the parameters $95 \%$ confidence intervals. Further, predictions of forage maize OMD were evaluated by residual analysis as described by St-Pierre (2003). Predicted values were centred by subtracting the mean of predicted values from each prediction within laboratory method. This centred data points to a mean value of zero. Prediction equations were evaluated by regressing residual values (observed - predicted) on centred predicted values using the REG procedure (SAS Inc., 20020-2003, Release 9.2; SAS Institute Inc. Cary, NC). Slope and intercept of the regression lines were orthogonal and can thereby be assessed independently. Slopes and intercepts of regression equations were used to determine the presence of linear and mean biases (St-Pierre, 2003). Root mean square error of prediction (RMSEP) was calculated as:

$$
\text { RMSEP }=\sqrt{ }\left[\Sigma(\text { Observed }- \text { Predicted })^{2} / n\right] .
$$

Additionally, performance of the in vitro laboratory methods and direct $\mathrm{D}$-value calibration by NIRS was further evaluated by regressing residuals vs centred forage maize NDF or starch concentration using simple regression. 


\section{Results}

\section{Digestibility related measures of the forage maize and performance of the new NIRS calibration}

In situ determined and NIRS predicted iNDF values, and observed $\left(\mathrm{OMD}_{\text {IN SITU }}\right.$; equation 1$)$ and predicted OMD of the forage maize across hybrids, sites and harvests are presented in Table 1. Values of OM solubility generated from the EFOS method
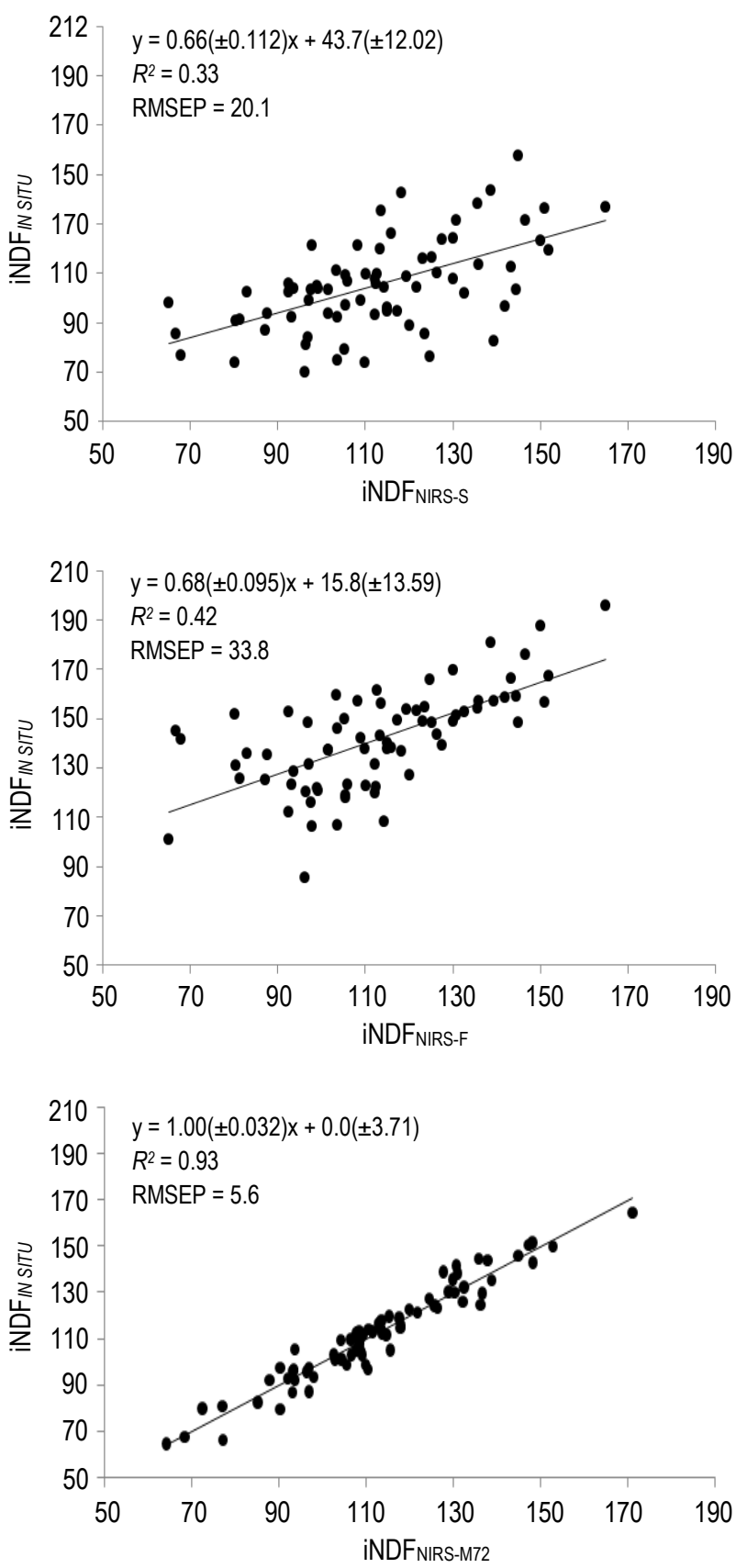

Figure 1. Relationships between predicted (NIRS-S - the Swedish NIRS calibration; NIRS-F - the Finnish NIRS calibration; NIRS-M72 - forage maize NIRS calibration) and observed (in situ determined) indigestible neutral detergent fibre (iNDF) for all forage maize samples $(n=72)$. Coefficient of determination $\left(R^{2}\right)$ and root mean square error of prediction (RMSEP, $\mathrm{g} \cdot \mathrm{kg}^{-1}$ are given to allow evaluation of the regression equations were generally lower than the values using the VOS method. The range of in situ determined iNDF was not reflected in either the Finnish or Swedish NIRS predicted iNDF. The existing Finnish NIRS calibrations predicted higher minimum and maximum values of iNDF compared to the in situ derived iNDF. The $\mathrm{OMD}_{\text {NIRS-F }}$ was generally slightly lower than other values of predicted OMD.

The best $\mathrm{iNDF}_{\text {NIRS }}$ calibration with 72 forage maize samples was achieved using mathematical treatments of the second order derivative $(2,4,4,1)$ and SNV\&D. The $R^{2}$ value for the best calibration was 0.92, and SEC and SECV were rather low (5.9 and $\left.10.0 \mathrm{~g} \cdot \mathrm{kg}^{-1} \mathrm{DM}\right)$. Cross validated coefficient of determination (1-VR) was lower than $R^{2}$ of the calibration ( 0.78 and 0.92 , respectively).The ratio $\mathrm{SD} / \mathrm{SECV}$ was 2.2 .

\section{Evaluation of predictions of concentrations of iNDF}

Linear regression analysis of $\mathrm{iNDF}_{I N \text { SITU }}$ on NIRS predicted iNDF from Sweden and Finland and from new maize calibration ( $\mathrm{iNDF}_{\mathrm{NIRS}-\mathrm{M} 72)}$, and RMSEP are presented in Figure 1. Slope of the fitted line of observed vs model predicted was different from unity $(P<0.05)$ for both Swedish and Finnish NIRS predictions of iNDF. Slope of the fitted line of observed vs model predicted was 1.00 for $\mathrm{iNDF}_{\text {NIRS-M72. }}$. The RMSEP was greater for $\mathrm{iNDF}_{\text {NIRS-F }}$ than for $\mathrm{iNDF}_{\text {NIRS-S }}$, but iNDF $\mathrm{NIRS-F}_{\text {Fas }}$ slightly more precise than iNDF $_{\text {NIRS-S. }}$ Residual analysis showed that $\mathrm{iNDF}_{\text {NIRS-s }}$ under-predicted $\mathrm{iNDF}_{\text {IN SITU }}$ and iNDF NIRS-F $_{\text {F }}$ over-predicted iNDF $(P<0.001$; Table 2$)$. The bias decreased with increasing values of iNDF $_{\text {NIRS-S }}$, but that was not the case for the NIRS predictions of iNDF from Finland $(P<0.001$; Table 2).

Table 2. Assessment of source of bias based on regression analysis of residuals of indigestible neutral detergent fibre (iNDF) and organic matter digestibility (OMD) predicted by near infrared reflectance spectroscopy (NIRS) and from different laboratory methods ${ }^{1}$

\begin{tabular}{lrrrrlc}
\hline Predictor $^{2}$ & \multicolumn{1}{l}{ Intercept SE } & $P$-value & Slope & SE & $P$-value \\
\hline iNDF $_{\text {NIRS-S }}$ & 7.4 & 2.09 & $<0.001$ & -0.34 & 0.112 & $<0.001$ \\
iNDF $_{\text {NRS-F }}$ & -28.9 & 1.93 & $<0.001$ & -0.32 & 0.095 & $<0.001$ \\
OMD $_{\text {EFOS }}$ & 14.2 & 2.32 & $<0.001$ & -0.28 & 0.076 & $<0.001$ \\
OMD $_{\text {vOS }}$ & 14.2 & 1.95 & $<0.001$ & 0.03 & 0.082 & 0.74 \\
OMD $_{\text {NIRS-F }}$ & 15.2 & 1.90 & $<0.001$ & -0.18 & 0.063 & $<0.01$ \\
\hline
\end{tabular}

${ }^{1}$ residual values were calculated as the difference between the observed and predicted values. The 288-h ruminal in situ determined iNDF and OMD predicted from that (Huhtanen et al., 2013) were used as observed values; ${ }^{2}$ iNDF $_{\text {NIRS-S }}$ - from the Swedish NIRS calibration; iNDF $_{\text {NIRS-F }}$ - from the Finnish NIRS calibration; OMD FES $_{\text {N }}$ - predicted from the in vitro enzyme digestible organic matter (Weisbjerg and Hvelplund, 1993); $\mathrm{OMD}_{\text {vos }}$ - predicted from rumen fluid organic matter solubility (Lindgren, 1979); $\mathrm{OMD}_{\text {NIRS-F }}-$ OMD predicted based on the Finnish NIRS calibration; ${ }^{3} \mathrm{SE}$ - standard error 


\section{Evaluation of OMD predictions}

Linear regressions of $\mathrm{OMD}_{I N \text { SITU }}$ values on values obtained using the other methods to determine OMD are presented in Figure 2. Slopes of the fitted regression equations were significantly different from unity $(P<0.05)$ for $\mathrm{OMD}_{\mathrm{EFOS}}$ and $\mathrm{OMD}_{\text {NIRS-F }}$ but not for $\mathrm{OMD}_{\mathrm{vos}}$ (Figure 2). The RMSEP was greatest for $\mathrm{OMD}_{\mathrm{EFOS}}$ and smallest for $\mathrm{OMD}_{\mathrm{VOS}}$
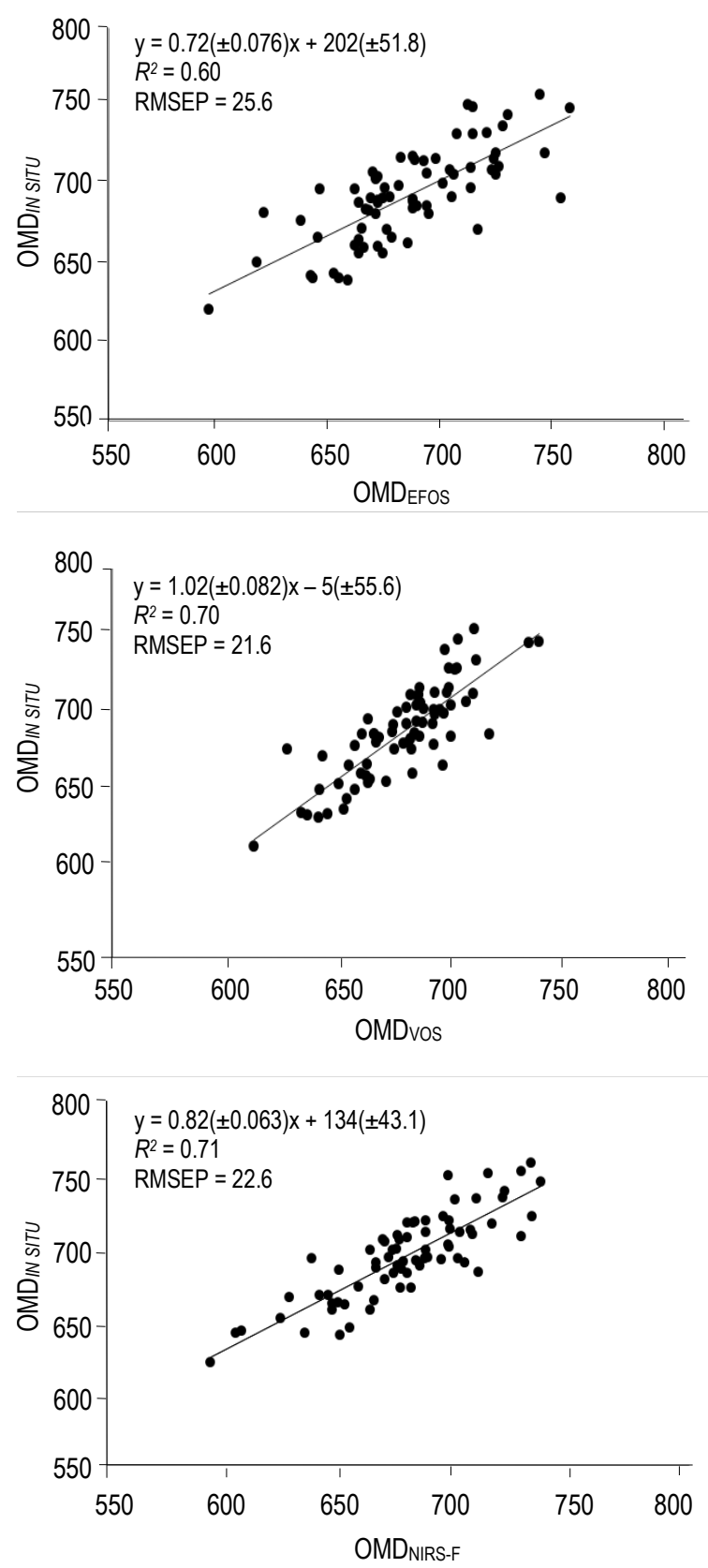

Figure 2. Relationships between predicted (EFOS - enzyme digestible organic matter; VOS - rumen fluid organic matter solubility; NIRS-F - the Finnish NIRS calibration) and observed (in situ determined) organic matter digestibility (OMD) for all maize hybrids $(n=72)$. Coefficient of determination $\left(R^{2}\right)$ and root mean square error of prediction (RMSEP, $\mathrm{g} \cdot \mathrm{kg}^{-1}$ ) are given to allow evaluation of the regression equations
(Figure 2). Analysis of the residuals when comparing $\mathrm{OMD}_{I N S I T U}$ and predictions of OMD is presented in Table 2. Residual analysis showed that all the methods systematically slightly under-predicted $\mathrm{OMD}_{I N \text { SITU }}(P<0.001$; Table 2$)$, but the bias decreased with increasing values of $\mathrm{OMD}_{\mathrm{EFOS}}$ and $\mathrm{OMD}_{\text {NIRS-F }}(P<0.01$; Table 2$)$. There was no significant slope bias for $\mathrm{OMD}_{\mathrm{voS}}(P=0.74)$.
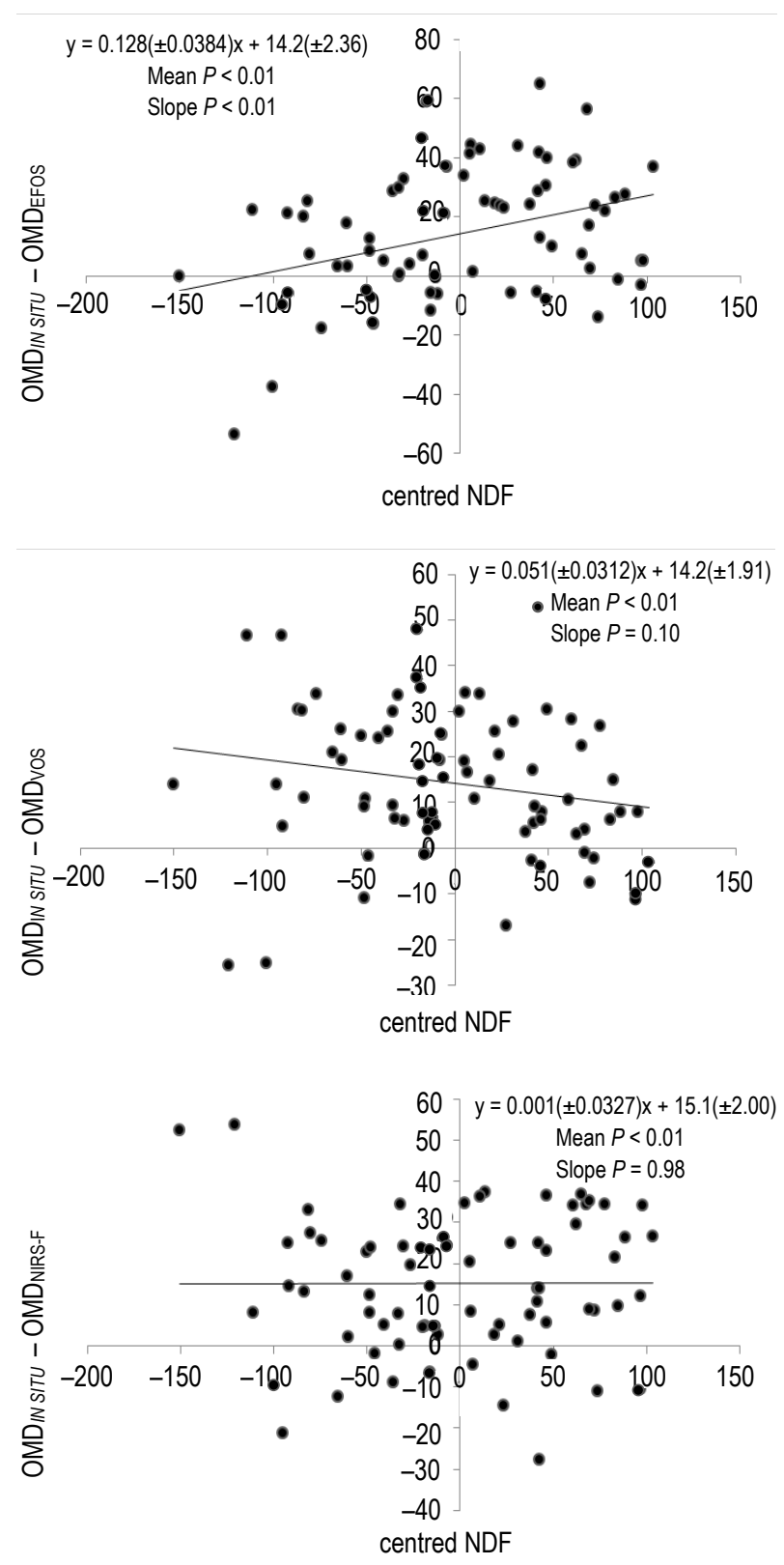

Figure 3. Plot of residuals (observed - predicted) vs centred neutral detergent fibre (NDF) concentration in forage maize samples $(n=72)$. In situ determined organic matter digestibility $\left(O M D_{\text {IN SITU }}\right)$ was used as observed values. Predicted values of organic matter digestibility were generated from enzyme digestible organic matter ( $\left.O M D_{\text {EFOS }}\right)$, rumen fluid organic matter solubility $\left(O M D_{\text {vos }}\right)$ and the Finnish NIRS calibration of organic matter digestibility (OMD $D_{\text {NIRS-F) }}$. The NDF values were centered by subtracting the mean of all values from each value. $P$ - values of mean and slope biases are given 


\section{Effects of forage maize iNDF concentration on OMD predictions}

The residual analysis of predicted OMD based on the EFOS and VOS methods generated a significant or tendency to a linear relationship to centred NDF concentrations ( $P \leq 0.10$; Figure 3$)$. Further, the analysis of residuals vs centred NDF concentrations in the forage maize samples resulted in significant mean biases for all three evaluated laboratory methods $(P<0.01)$. The results for the analysis of residuals vs centred starch concentration of all forage maize samples was a mirror image of Figure 3, i.e. indicated the same results, and are therefore not presented in the paper.

\section{Discussion}

Forage maize samples and performance of the new NIRS calibration. The objective of this study was to compare different analytical methods used for predicting OMD and iNDF concentrations in forage maize, taking into account effects of hybrid, site and maturity on the difference between observed and predicted values. Unlike other recent assessments of analytical techniques for evaluating forage quality (e.g., Gosselink et al., 2004; Krizsan et al., 2012) the plant material in this study only included one forage type. The NIRS predictive ability of feed value traits of forage maize covering a wide variation in phenological growth stages at high latitudes is not well-known. Distribution of hybrids, sites and harvesting times in this study provided a large range of agronomic performance and a novel material for evaluation of analytical methods and NIRS predictions of forage maize feed value at high latitudes. Further, the forage samples represented a wide range in attributes compared to maize grown in more southern latitudes as indicated by the variations in DM, starch and NDF concentrations (Givens et al., 1995; Givens and Deaville, 2001; Keady et al., 2008).

Prediction errors for iNDF ${ }_{\text {IN SITU }}$ with iNDF $\mathrm{NIRS-M72}$ calibration were low. The calibration was made from the same samples as iNDF ${ }_{\text {IN SITU }}$ was determined for. Therefore, some reservations should be made to the good performance of it. This can be seen from 1-VR that was lower than $R^{2}$ of the calibration. Further, the difference between SEC and SECV was quite large and SD/SECV ratio rather small. However, relatively small SECV, which corresponds to SE of $12.1 \mathrm{~g} \cdot \mathrm{kg}^{-1}$ in OMD (equation 1), suggests that NIRS has a great potential to predict iNDF and OMD of forage maize accurately and precisely.
According to Sinnaeve et al. (1994) a SD/SECV ratio larger than 3.0 indicates that the calibration could be used for quantitative purposes, while a ratio between 2.5 and 3.0 indicates that the calibration should be used only for screening purposes. Commercial forage maize NIRS calibrations of iNDF need to be made from more samples and preferably evaluated from an independent set of data points.

NIRS predictions of iNDF. Neither Swedish nor Finnish NIRS calibration generated satisfactory predictions of the iNDF concentration in forage maize samples in this study. For the Finnish NIRS calibration of forage iNDF it can simply be explained by a lack of forage maize samples included in the calibration dataset. However, the Swedish calibration included samples of ensiled as well as fresh forage maize. Results of the Nordic ring test by Lund et al. (2004) pointed out a large between-laboratory variation in determined iNDF concentrations of different feed samples. Poor between-laboratory reproducibility of the in situ technique has also been reported for ruminal protein degradability (Madsen and Hvelplund, 1994). The Nordic feed evaluation system NorFor introduced a standardized protocol for in situ determination of iNDF in 2007 aiming to decrease variation observed between laboratories in Nordic countries (Eriksson et al., 2007). The standardized procedure of in situ determination of iNDF was later presented by Åkerlind et al. (2011). The procedure mainly introduced recommendations of bag cloth type, numbers of animals and length of incubation (Åkerlind et al., 2011). However, many factors still seem to contribute to variation in analytical precision of the iNDF procedure between laboratories as indicated by the most recent Nordic ring test by Eriksson et al. (2012). A decomposition of the observed variance components has not been conducted and the greatest sources of variation in the procedure have not been properly identified. Further, implementation of the standard protocol might differ between laboratories and makes it difficult to correctly interpret results of ring tests. Another major problem complicating comparisons of results obtained using different analytical procedures iNDF in ring tests, as well as in this study, is the need for relevant in vivo data with which to compare results with; to identify which procedure gives the most biologically correct values. A reason for the poor performance of Swedish NIRS predictions of iNDF in this study could be that reference data in the calibration originated from different laboratories using different procedures. 
Despite that there were no forage maize samples in the Finnish reference data set of iNDF the Finnish iNDF calibration generated more precise predictions than the Swedish iNDF calibration. Accuracy and robustness of NIRS calibrations depend on the quality and representativeness of the calibration data set. The calibration sample population must cover all sources of variation in chemical, physical and botanical characteristics of the samples to be analysed (Deaville and Flynn, 2000). To generate reliable NIRS calibrations used for quantitative purposes all forage types to be predicted should be included in the calibration sample population. Different sample types produce different NIR spectra and therefore calibration data set must cover even small spectral variations to generate accurate and precise predictions. Strong relationships between OMD predictions obtained from the NDF and iNDF values with other laboratory methods (EFOS, VOS and direct D-value calibration) supported this suggestion $(r=0.75,0.83$ and 0.84 , respectively). Furthermore, accurate and precise predictions of in vivo OMD using the current iNDF method (Krizsan et al., 2012) for a large sample set including maize silages support the reliability of the iNDF in situ method.

Reference method for in vivo OMD determination. The ideal reference values for OMD in vivo digestibility determined in sheep fed at maintenance, but for practical reasons this is not possible to apply routinely. Digestibility determinations in vivo require much large amount of the forage samples and are more cost demanding compared to laboratory methods. Instead of OMD determined in vivo, we used predictions of OMD based on forage iNDF and NDF concentrations as reference method in the present study. This decision relied on findings by Huhtanen et al. (2006) and Krizsan et al. (2012) that OMD predicted from forage iNDF concentration generated least prediction error compared to in vivo digestibility data. The method was also more uniform across forage types than any other laboratory method evaluated. Hetta et al. (2012) modelled in vivo OMD from whole plant forage maize samples based on in vitro gas production recordings. However, the data was not related to in animal determined in vivo OMD values. In a recent review by Huhtanen et al. (2013) it was concluded that predicting OMD from forage iNDF and NDF concentrations provided smaller prediction error compared to in vivo OMD equation that only included the concentration of iNDF. The EFOS method, which has been recommended for evaluating forage maize (Åkerlind et al., 2011), had a larger prediction error of OMD for forage maize samples in the equa- tion developed by Søegaard et al. (2001) than the general iNDF-equation (across forage types and not forage specific) developed by Huhtanen et al. (2006).

Prediction of OMD based on EFOS. The EFOS method generated the poorest prediction of $\mathrm{OMD}_{I N \text { SITU }}$ compared with the other methods evaluated in this study. The prediction error of $\mathrm{OMD}_{\text {IN SITU }}$ in this study was smaller than that presented by Søegaard et al. (2001) when developing the relationship between in vivo OMD of forage maize and the EFOS method. Despite this, EFOS is the recommended laboratory method for whole crop maize in the Nordic feed evaluation system NorFor (Åkerlind et al., 2011). Poor prediction of $\mathrm{OMD}_{\text {IN SITU }}$ might be due to limitations of enzymes compared to rumen fluid microorganisms used in vitro, in agreement with other recent comparisons in the literature (Koukolová et al., 2004; Jančík et al., 2011; Krizsan et al., 2012). Further, differences between determined in vitro and in vivo digestibility may vary among forage types and species. Predictions of in vivo OMD can theoretically be improved by developing forage-specific equations (Huhtanen et al., 2006), and even specific equations for different grass species as suggested by Jančík et al. (2011). However, such equations are not useful for evaluating diets and forage mixtures in practice on farms, and not either in plant breeding programmes for comparing individual hybrids and varieties, since the specific botanical composition and taxonomy of forages is difficult and laborious to determine.

The strong slope bias in the analysis of residuals vs centred NDF concentrations indicated that the enzyme method was not able predict accurately the effects of growing conditions, hybrid or plant maturity on OMD. Despite its poor predictive ability, the EFOS method has a major advantage in that rumen cannulated animals are not required. Thus, the technique should be easier to implement in laboratories and may be easier to standardize, like other enzymatic methods (Jones and Theodorou, 2000).

Prediction of OMD based on VOS. Although the regression equation related to the VOS technique described by Lindgren (1979) was primarily developed for predicting in vivo OMD digestibility of perennial grasses and legumes, in this experiment the VOS method was the best predictor of OMD ${ }_{\text {INSITU }}$ This is in accordance with previous reports that the VOS method is a good predictor of in vivo OMD (Krizsan et al., 2012). The under-prediction of OMD adapting the VOS technique was greater in this study than what Krizsan et al. (2012) found when comparing the predictions with values of in vivo OMD in maize 
silage samples. The VOS technique has the advantage over other in vitro methods of using smaller amount of rumen fluid and longer incubation period thereby being less sensitive to fluctuations in condition of the inoculum (Krizsan et al., 2012). The tendency for a slope bias in the analysis of residuals vs centred NDF concentrations indicated that the method was affected by either growing conditions, hybrid or plant maturity.

Predicting OMD by NIRS. Prediction of $\mathrm{OMD}_{\text {IN SITU }}$ from the Finnish D-value NIRS calibration displayed mean and slope biases, but prediction was almost as precise as by $\mathrm{OMD}_{\mathrm{vos}}$. One of the limitations associated with NIRS predictions of OMD is that pepsin-cellulase OMD as reference method requires forage-specific equations (Nousiainen et al., 2003). Although NIRS calibration has performed well for a multitude of forage species (Nousiainen, personal communication), reference plant material in the Finnish calibration did not include any forage maize samples. Taking these factors into consideration, performance of NIRS predictions of in vivo OMD in forage maize cultivated at high latitudes have potential to be improved by extending the calibration sample set to also include forage maize samples with a wide variation in maturity. This is also supported by the results by Deaville et al. (2009), who achieved better predictive ability by NIRS of in vivo digestibility and metabolizable energy values than of in vitro traits and chemical composition data of whole crop cereals. Further, it was the technique that performed best in the analysis of residuals vs centred NDF concentrations. This indicates that the method has similar prediction error irrespective of growing conditions and plant maturity, factors that are known to influence forage maize quality (Cox et al., 1994).

\section{Conclusions}

Both Swedish and Finnish near infrared reflectance spectroscopy (NIRS) predictions of forage maize indigestible neutral detergent fibre (iNDF) concentrations were biased. None of the laboratory methods and equations relating to in vivo organic matter digestibility (OMD) in this study qualified for unbiased prediction of forage maize feed value. In comparison, all three prediction methods that were evaluated in this study systematically underestimated $\mathrm{OMD}_{I N}$ SITU concentration in forage maize. Additionally, regression analysis of the residuals indicated that both $\mathrm{OMD}_{\mathrm{EFOS}}$ and $\mathrm{OMD}_{\text {NIRS-F }}$ were associated with slope biases, which will result in an even greater underestimation of feed value of forage maize with decreased digestibility. The NIRS was the technique least sensitive to effects of hybrid, site and maturity in its predictions of OMD. For $\mathrm{OMD}_{\text {EFOS }}$ and $\mathrm{OMD}_{\mathrm{VOS}}$, a larger reference data set is needed to facilitate accurate prediction of in vivo OMD. Based on results of this study we conclude that NIRS predictions of OMD can be a promising tool in the evaluation of feed value of forage maize at high latitudes if NIRS calibrations of iNDF including forage maize samples are generated.

\section{References}

Åkerlind M., Weisbjerg M., Eriksson T., Tøgersen R., Udén P., Ólafsson B.L., Harstad O.M.,Volden H., 2011. Feed analyses and digestion methods. In: H. Volden (Editor). NorFor-The Nordic Feed Evaluation System. Wageningen Acad. Publication, Wageningen (The Netherlands), pp. 41-54

Bal M.A., Coors J.G., Shaver R.D., 1997. Impact of the maturity of corn for use as silage in the diets of dairy cows on, intake, digestion and milk production. J. Dairy Sci. 80, 2497-2503

Cox W.J., Chereny J.H., Chereny D.J.R., Pardee W.D., 1994. Forage quality and harvest index of corn hybrids under different growing conditions. Agron. J. 86, 277-282

Deaville E.R., Flynn P.C., 2000. Near infrared reflectance spectroscopy: An alternative approach to forage quality evaluation. In: D.I. Givens, E. Owen, R.F.E. Axford, H.M. Omed (Editors). Forage Evaluation in Ruminant Nutrition. CABI, Wallingford, pp. $301-320$

Deaville E.R., Humphries D.J., Givens D.I., 2009. Whole crop cereals 2. Prediction of apparent digestibility and energy value from in vitro digestion techniques and near infrared reflectance spectroscopy and of chemical composition by near infrared reflectance spectroscopy. Anim. Feed Sci. Tech. 149, 114-124

Eriksson T., Lindberg E., Harstad O.M., Bævre L., Olafsson B.L., Weisbjerg M.R., Thørgersen R., 2007. NorFor in sacco standard. Available from http://norfor.info/Files/pdf-dokumenter/ pdf_lab/Analyses/NorFor_in_sacco_standard_070910.pdf (verified 23 March 2013)

Eriksson T., Krizsan S.J., Volden H., Eriksson T., Rinne M., Nissen H., Eriksen C., Brohede L., Vedder H., Weisbjerg M.R., 2012. Nordic ring test on NDF and NDF contents of tenfeed samples. In: Proceedings of the Nordic Feed Science Conference, Uppsala (Sweden). Swedish University of Agricultural Sciences, pp. 13-18

Givens D.I., Cottyn B.G., Dewey P.J.S., Steg A., 1995. A comparison of neutral detergent-cellulase method with other laboratory methods for predicting the digestibility in vivo of maize silages from three European countries. Anim. Feed Sci. Tech. $54,55-64$

Givens D.I., Deaville E.R., 2001. Comparison of major carbohydrate fractions and cell wall digestibility in silages made from older and newer maize genotypes grown in the UK. Anim. Feed Sci. Tech. 89, 69-82

Gosselink J.M.J., Dulphy J.P., Poncet C., Jailler M., Tamminga S., Cone J.W., 2004. Prediction of forage digestibility in ruminants using in situ and in vitro techniques. Anim. Feed Sci. Tech. 115, 227-246

Hetta M., Mussadiq Z., Gustavsson A.-M., Swensson C., 2012. Effects of hybrid and maturity on performance and nutritive characteristics of forage maize at high latitutdes, estimated using the gas production technique. Anim. Feed Sci. Tech. 171, 20-30 
Huhtanen P., Jaakkola S., Nousiainen J., 2013. An overview of silage research in Finland: from ensiling innovation to advances in dairy cow feeding. Agr. Food Sci. 22, 35-56

Huhtanen P., Kaustell K., Jaakkola S., 1994. The use of internal markers to predict total digestibility and duodenal flow of nutrients in cattle given six different diets. Anim. Feed Sci. Tech. 48, 211-227

Huhtanen P., Nousianen J., Rinne M., 2006. Recent developments in forage evaluation with special reference to practical applications. Agr. Food Sci.15, 293-223

Janĉik F., Rinne M., Homolka P., Čermák B., Huhtanen P., 2011. Comparison of methods for forage digestibility determination. Anim. Feed Sci. Tech. 169, 11-23

Jones D.I.H.,Theodorou M.K., 2000. Enzymatic techniques for estimating digestibility. In: D.I. Givens, E. Owen, R.F.E. Axfor, H.M. Omed (Editors). Forage Evaluation in Ruminant Nutrition. Oxon: CABI Publishing, pp. 155-173

Jordbruksverket, 2010. Swedish Board of Agriculture. Available fromhttp://www.jordbruksverket.se/amnesomraden/odling/andrajordbruksgrodor/majs/skordestatistik.html (verified 23 March 2013)

Keady T.W.J., Kilpatrick D.J., Mayn C.S., Gordon F.J., 2008. Effect of replacing grass silage with maize silages, differing in maturity, on performance and potential concentrate sparing effect of dairy cows offered two feed grass silages. Livest. Sci. 119, $1-11$

Koukolová V., Weisbjerg M.R., Hvelplund T., Lund P., Čermák B., 2004. Prediction of NDF degradation chracteristics of grass and grass/clover forages based on laboratory methods. J. Anim. Feed Sci.13, 691-708

Krizsan S.J., Nyholm L., Nousiainen J., Südekum K.H., Huhtanen P., 2012.Comparison of in vitro and in situ methods in evaluation of forage digestibility in ruminants. J. Anim. Sci. 90, 3162-3173

Lindgren E., 1979. Nutritive value of forages determined in vivo and with different laboratory methods (in Swedish). Rapport 45. Swedish University of Agricultural Sciences, Uppsala (Sweden)

Lindgren E., 1983. A new calibration of rumen fluid organic matter solubility to determine energy value in forages (in Swedish). Working paper. Department of Animal Nutrition and Management, Swedish University of Agricultural Sciences, Uppsala (Sweden)

Lund P., Weisbjerg M.R., Ahvenjärvi S., Huhtanen P., Udén P., Olafsson B.,Volden H., 2004. Nordic ringtest on iNDF content and NDF degradation characteristics in three feeds. J. Anim. Feed Sci.13, 139-142
Madsen J., Hvelplund T., 1994. Prediction of in situ protein degradability in the rumen. Results of a European ringtest. Livest. Prod. Sci. 39, 201-212

Mertens D.R., Allen M., Carmany J. et al., 2002. Gravimetric determination of amylase-treated neutral detergent fiber in feeds with refluxing in beakers or crucibles: Collaborative study. J. AOAC Int. 85, 1217-1240

Mussadiq Z., Hetta M., Swensson C.,Gustavsson A.M., 2012. Plant development, agronomic performance and nutritive value of forage maize depending on hybrid and marginal site conditions at high latitudes. Acta Agr. Scand. Sect. B. Soil PI. 62, $420-430$

Nousiainen J., Rinne M., Hellemäki M., Huhtanen P., 2003. Prediction of the digestibility of primary growth and regrowth grass silages from chemical composition, pepsin-cellulase solubility and indigestible cell wall content. Anim. Feed Sci. Tech.110, $61-74$

Sinnaeve G., Dardenne P., Agneessens R., Biston R., 1994. The use of near infrared spectroscopy for the analysis of fresh grass silage. J. Near Infrared Spectrosc. 2, 79-84

Søegaard K., Weisbjerg M.R., Thøgersen R., Mikkelsen M., 2001. Laboratory methods to determine digestibility in forages to cattle with special emphasis on starch-rich whole crop forages (in Danish). DJF. Rapport nr. 34. Husdyrbryg,Tjele (Denmark)

St-Pierre N.R., 2003. Reassessment of bias in predicted nitrogen flows to the duodenum by NRC 2001. J. Dairy Sci. 86, 344-350

Sutton J.D., Cammell S.B., Phipps R.H., Beever D.E., Humphries D.J., 2000. The effect of crop maturity on the nutritional value of maize silage for lactating dairy cattle. 2. Ruminal and postruminal digestion. Anim. Sci. 71, 391-400

Swensson C., Hetta M., Mussadiq Z., 2008. Phenological development of maize and its nutritive value importance for dairy cows under Swedish conditions. In: A. Hopkins, T. Gustafsson, J. Bertilsson, G. Dalin, N. Nilsdotter-Linde, E. Spörndly (Editors). Biodiversity and Animal Feed, Future Challenges for Grassland Production. Book of Abstracts, 22nd General Meeting of the European Grassland Federation, Swedish University of Agricultural Sciences, Uppsala (Sweden), p. 94

Weisbjerg M.R., Hvelplund T., 1993. Determination of Net Energy Content in Concentrate Supplements (in Danish). Forskningsrapport nr. 3. StatensHusdyrbrugsforsøg (Denmark), pp. 30 